\title{
Reliability of a seminar grading rubric in a grand rounds course
}

\author{
This article was published in the following Dove Press journal: \\ Journal of Multidisciplinary Healthcare \\ 8 September 2010 \\ Number of times this article has been viewed
}

\section{Eric J MacLaughlin' \\ David S Fikel \\ Carlos A Alvarez ${ }^{2}$ \\ Charles F Seifert ${ }^{3}$ \\ Amie T Blaszczyk ${ }^{2}$}

Texas Tech University Health Sciences School of Pharmacy, Department of Pharmacy Practice, 'Amarillo, ${ }^{2}$ Dallas, ${ }^{3}$ Lubbock, Texas, USA
Correspondence: Eric J MacLaughlin Texas Tech University Health Sciences Center School of Pharmacy, 1300 S Coulter St, Amarillo, TX 79106, USA

Tel +l 8063564000 ext 264

$\mathrm{Fax}+\mathrm{I} 8063564018$

Email eric.maclaughlin@ttuhsc.edu
Purpose: Formal presentations are a common requirement for students in health professional programs, and evaluations are often viewed as subjective. To date, literature describing the reliability or validity of seminar grading rubrics is lacking. The objectives of this study were to characterize inter-rater agreement and internal consistency of a grading rubric used in a grand rounds seminar course.

Methods: Retrospective study of 252 student presentations given from fall 2007 to fall 2008 . Data including student and faculty demographics, overall content score, overall communication scores, subcomponents of content and communication, and total presentation scores were collected. Statistical analyses were performed using SPSS, 16.0.

Results: The rubric demonstrated internal consistency (Cronbach's alpha $=0.826$ ). Mean grade difference between faculty graders was 4.54 percentage points ( $\mathrm{SD}=3.614)$, with $\leq 10$-point difference for $92.5 \%$ of faculty evaluations. Student self evaluations correlated with faculty scores for content, communication, and overall presentation $(\mathrm{r}=0.513, \mathrm{r}=0.455$, and $\mathrm{r}=0.539$; $P<0.001$ for all respectively). When comparing mean faculty scores to student's self-evaluations between quintiles, students with lower faculty evaluations overestimated their performance, and those with high faculty evaluations underestimated their performance $(P<0.001)$.

Conclusion: The seminar evaluation rubric demonstrated inter-rater agreement and internal consistency.

Keywords: seminar, public speaking, evaluation, grand rounds

\section{Introduction}

The ability to communicate effectively and utilize evidence-based medicine principles are core competencies for health care professionals. ${ }^{1}$ Pharmacists, physicians, nurses, and other health care professionals must collaborate and communicate in an interdisciplinary fashion to integrate current research findings into clinical practice.

Evaluating the reliability and validity of various forms of medical literature, and being able to educate both the public and other healthcare professionals, are important competencies in training programs and licensure..$^{2-6}$ Upon graduation, healthcare professionals frequently will be required to research and evaluate literature to answer clinical questions. In addition, many will be called upon to provide various educational presentations, either as an informal discussion or lecture, or formal continuing education seminars.

One method by which effective communication methods and use of evidencebased medicine principles may be assessed is through a seminar course. Since 1996, two seminar courses designed to instill these skills have been required as part of 
the Doctor of Pharmacy curriculum at the Texas Tech University Health Sciences School of Pharmacy. The Grand Rounds courses are 2-credit courses that occur in the fall and spring of the fourth professional year (PHAR 4241 and 4242 respectively) across three campuses (Amarillo, Dallas, and Lubbock, Texas, USA). Each semester, a student must present one 40-minute seminar on a timely and/or controversial topic, with 5-10 minutes allotted for questions and answers. Topics suitable for presentations are those that would be interesting to practicing pharmacists. These may include new medications, therapeutic controversies, practice management issues, pharmacy-related law, medical ethics, or pharmacoeconomics.

The framework utilized for development of student presentations is based on the Accreditation Council on Pharmacy Education, Accreditation Standards for Continuing Pharmacy Education. ${ }^{7}$ Learning outcomes for the course include the ability to: 1) Define a pharmacy practice topic that is appropriately focused and is of general interest to pharmacy practitioners; 2) Design an effective presentation, synthesizing clinical literature and incorporating both basic science and pharmacy practice content, which meets ACPE guidelines; 3) Utilize a faculty mentor for feedback in the research, development, and execution of a slide presentation; 4) Demonstrate effective public communication skills; and 5) Self-evaluate presentation content and communication skills.

Prior to 2006, one faculty member would grade the content of a student seminar and another would grade communication skills. A common complaint by students was their feeling that the presentation evaluations were overly subjective, and resulted in significant grade discrepancies. Informal polling of faculty involved with grading tended to corroborate this assumption, which was consistent with respondents to a faculty survey of communication skills development. ${ }^{8}$ This was felt in large part due to lack of specific, descriptive, objective criteria that outlined the competencies and expectations clearly in the grading form. In addition, students would sometimes complain that evaluations would differ depending upon campus location or by various levels of faculty rank.

In 2006, a new grading rubric was designed to assess both the content and communication skills of students. The grading rubric that was developed incorporated specific outcomes for each subcategory of seminar content and communication, and thus appeared to be more objective and subject to less inter-rater variability. In developing this tool, a review of the health sciences and education literature, Internet search, and informal survey of academic pharmacy faculty was conducted via the American College of Clinical Pharmacy list serve. The course coordinator (EJM) constructed the first draft of the rubric, creating specific sections and subsections that assessed and weighted specific criteria. The criteria selected were felt essential components of a professional seminar, consistent with the goals and objectives of the Grand Rounds course. After construction, the rubric was distributed to faculty course members for review and further refinement.

In addition to developing a new rubric in 2006, a new student self-assessment process was incorporated into the course. By requiring students to view and evaluate their own presentation using the same rubric that the faculty used, it was hoped that this would provide students more insight into the grade they received and enhance development of their presentation skills.

In developing the rubric (Appendix 1), it was noted that little-to-no literature was available describing the validity or reliability of seminar evaluation tools. While a seminar grading rubric has been published in the pharmacy education literature, ${ }^{9}$ and numerous public speaking rubrics are widely available on the Internet, the vast majority of these assessments instruments appear somewhat subjective nor are they specific for health professionals. In addition, to our knowledge, no study has assessed the utility or reliability of student self-evaluation of performance in a pharmacy seminar course.

The primary objectives of this study were to assess the consistency of faculty scoring using the revised grading rubric, and to compare the results of student self-evaluations to faculty evaluations. Secondary objectives included assessing the internal consistency of the rubric and determining if differences exist in rubric scoring depending on campus location or other factors that may influence faculty evaluations (eg, academic rank).

\section{Methods}

This was a retrospective study of fourth year Doctor of Pharmacy students enrolled in the fall 2007, spring 2008, and fall 2008 grand rounds courses (PHAR 4241 and 4242 for the fall and spring courses, respectively). Students enrolled attended a two-hour course orientation each summer that outlined the expectations and requirements of the courses and reviewed the grading rubric.

Two independent faculty members graded each presentation using the revised rubric. Written instructions for 
using the rubric were included on the evaluation form and a "frequently asked questions" document was distributed to all graders. For each student presentation, two faculty members were nonrandomly selected from the faculty pool to serve as graders. Thus, faculty graders potentially varied for each student presentation. Each student's final presentation score was determined by averaging the two faculty grades. Streaming videos were made of all presentations and uploaded to WebCT 6 (Blackboard Inc, Washington, DC, USA). Students were required to view their presentations, and complete a self-assessment of their performance using the same grading rubric used by the faculty graders. While the student's self-assessment grade was not incorporated as part of their final course grade, it was required in order to successfully complete the course (ie, failure to do so would result in an "incomplete").

Data from faculty evaluations of presentations and student self-evaluations were collected. This data included the mean overall presentation grade, overall content and communication grades, and each subcategory of the content and communication assessment. The professorial rank of the faculty grader (ie, clinical instructor [resident], assistant professor, associate professor, or professor) was also collected. Student baseline demographics including age, gender, race, campus location, and pre-course enrollment GPA were obtained from the Office of Student Services. All data was input and maintained in a Microsoft Excel (Redmond, VA, USA) spreadsheet. Study approval was obtained from the Institutional Review Board.

\section{Statistical analysis}

Data were converted from Microsoft Excel to SPSS Version 16.0 (Chicago, Ill, USA). Descriptive statistics were used for baseline student information. Internal consistency of the rubric was assessed using Cronbach's alpha, which provides a point-estimate measure of how well items in the rubric correlate with each other. Cronbach's alpha was calculated using the raw scores for the 15 items in the rubric based upon scores assigned from each faculty evaluation of each student presentation.

Pearson's correlation coefficient was used to determine the correlation between the mean faculty presentation grade and student self-evaluation. Agreement of grades between faculty pairs was operationally defined as the absolute value of the difference of scores assigned by faculty pairs for each student grand rounds presentation. For example, if student $\mathrm{A}$ received an overall score of 87 by faculty $\mathrm{X}$ and 89 by faculty $\mathrm{Y}$, the grade agreement score for student A was $|87-89|=2$. This definition provided an interval-level measure for each student presentation of how well the scores of faculty pairs agreed.

To test for differences in mean grade agreement scores between groups (ie, student gender, campus, semester), t-test and analysis of variance methods were used. Additionally, a Pearson's correlation coefficient was calculated to determine if grade agreement scores were associated with student age. A $P$-value of $<0.05$ was set for level of significance.

\section{Results}

From fall of 2007 through fall of 2008, 168 students were enrolled in the grand rounds courses (PHAR 4241 and 4242). These students delivered 252 presentations over 3 campuses (Amarillo $\mathrm{n}=85$, Dallas $\mathrm{n}=109$, and Lubbock $\mathrm{n}=58$ ). All faculty evaluation data were available for analysis. Two student self-evaluations were excluded due to incomplete data. Student demographics and pre-course enrollment GPA are presented in Table 1.

Internal consistency of the rubric as measured by Cronbach's alpha was 0.826 . While a Cronbach's alpha of 0.70 or greater is often cited as being deemed acceptable, ${ }^{10}$ some suggest a minimum of $0.80 .{ }^{11}$ However, the level of acceptability may be higher or lower depending upon the purpose of the examination. ${ }^{11}$ For this assessment, the rubric demonstrated acceptable internal consistency.

The mean grade agreement score for the 252 presentations was 4.54 percentage points $(\mathrm{SD}=3.614)$. Grade agreement scores ranged from a low of 0 percentage points (both graders gave the same overall score) to a high of 20 percentage points (one grader gave a $96 \%$ while the other gave a $76 \%$ ). Of note though, $92.5 \%$ of the grade agreement scores were 10 percentage points or less and $67.9 \%$ of the grade differences were 5 percentage points or less (Figure 1).

Mean grade agreement scores (difference in student presentation grades between faculty grader 1 and 2) for the three campuses were $4.6 \pm 4.0,4.9 \pm 3.6$ and $3.6 \pm 2.8$ (mean $\pm \mathrm{SD}$ ). There was no significant difference in mean grade agreement depending upon campus location $(P=0.065)$. In addition, there was no difference based on age ( $\mathrm{r}=0.045, P=0.476$ ), gender (mean grade for males was $4.9 \pm 3.9$ versus $4.2 \pm 3.4$ for females; $P=0.138$ ), and results did not vary by semester (mean grades $5.01 \pm 3.78$, $4.21 \pm 3.55$, and $4.37 \pm 3.48 ; P=0.311$ ).

To determine if differences in faculty rank may have affected scoring, each pair of faculty graders were categorized 
Table I Baseline student demographics

\begin{tabular}{|c|c|c|c|c|c|}
\hline \multirow[t]{2}{*}{ Demographic } & & \multicolumn{4}{|l|}{ Campus } \\
\hline & & $\begin{array}{l}\text { Amarillo } \\
(n=55)\end{array}$ & $\begin{array}{l}\text { Dallas } \\
(n=73)\end{array}$ & $\begin{array}{l}\text { Lubbock } \\
(n=39)\end{array}$ & $\begin{array}{l}P \text {-value } \\
\text { among campuses }\end{array}$ \\
\hline Age $(y r s)^{\mathrm{a}}$ & $29.9 \pm 5.8$ & $31.2 \pm 6.3$ & $28.1 \pm 4$ & $28.3 \pm 7$ & $0.006^{b}$ \\
\hline \multicolumn{6}{|l|}{ Gender } \\
\hline Male (\%) & 44.6 & 49.1 & 35.6 & 53.8 & 0.124 \\
\hline \multicolumn{6}{|l|}{ Race } \\
\hline Caucasian (\%) & 60 & 72.7 & 42.5 & 76.9 & $<0.00 \mathrm{I}^{\mathrm{c}}$ \\
\hline Asian (\%) & 16 & 3.6 & 31.5 & 2.6 & \\
\hline Hispanic (\%) & 17 & 20 & 13.7 & 17.9 & \\
\hline Other (\%) & 7.2 & 3.6 & 12.3 & 2.6 & \\
\hline Pre-enrollment & $88.5 \pm 4.1$ & $87.4 \pm 3.8$ & $89.2 \pm 4.3$ & $88.6 \pm 4$ & $0.05^{d}$ \\
\hline GPA (\%) ${ }^{a}$ & & & & & \\
\hline
\end{tabular}

Notes: ${ }^{\mathrm{a}}$ Expressed as mean $\pm \mathrm{SD}$; ${ }^{\mathrm{D}}$ Difference exists between Amarillo and Dallas; ' $\mathrm{Dallas}$ differs from Amarillo and Lubbock; ${ }^{\mathrm{d}} \mathrm{Difference}$ exists between Amarillo and Dallas.

as having the same academic rank, having ranks that differ by one (eg, assistant vs associate professor), having ranks that differ by two (eg, assistant vs full professor) or having ranks that differ by three (eg, resident vs full professor). Among the four strata of faculty grader pairs, mean grade agreement scores ranged from 3.89 to 4.95 (Table 2). These differences were not significant $(P=0.553)$, suggesting that grade agreement was not biased by differences in faculty rank.
In order to receive their grade, students were required to watch a video of their presentation and complete the same evaluation form as the faculty graders. There was a statistically significant correlation between the overall presentation grade, overall content score, and overall communication score between the student's self-evaluation and faculty-assessed performance (Table 3).

To determine if there was a difference in how students evaluated their performance based on the grade they received

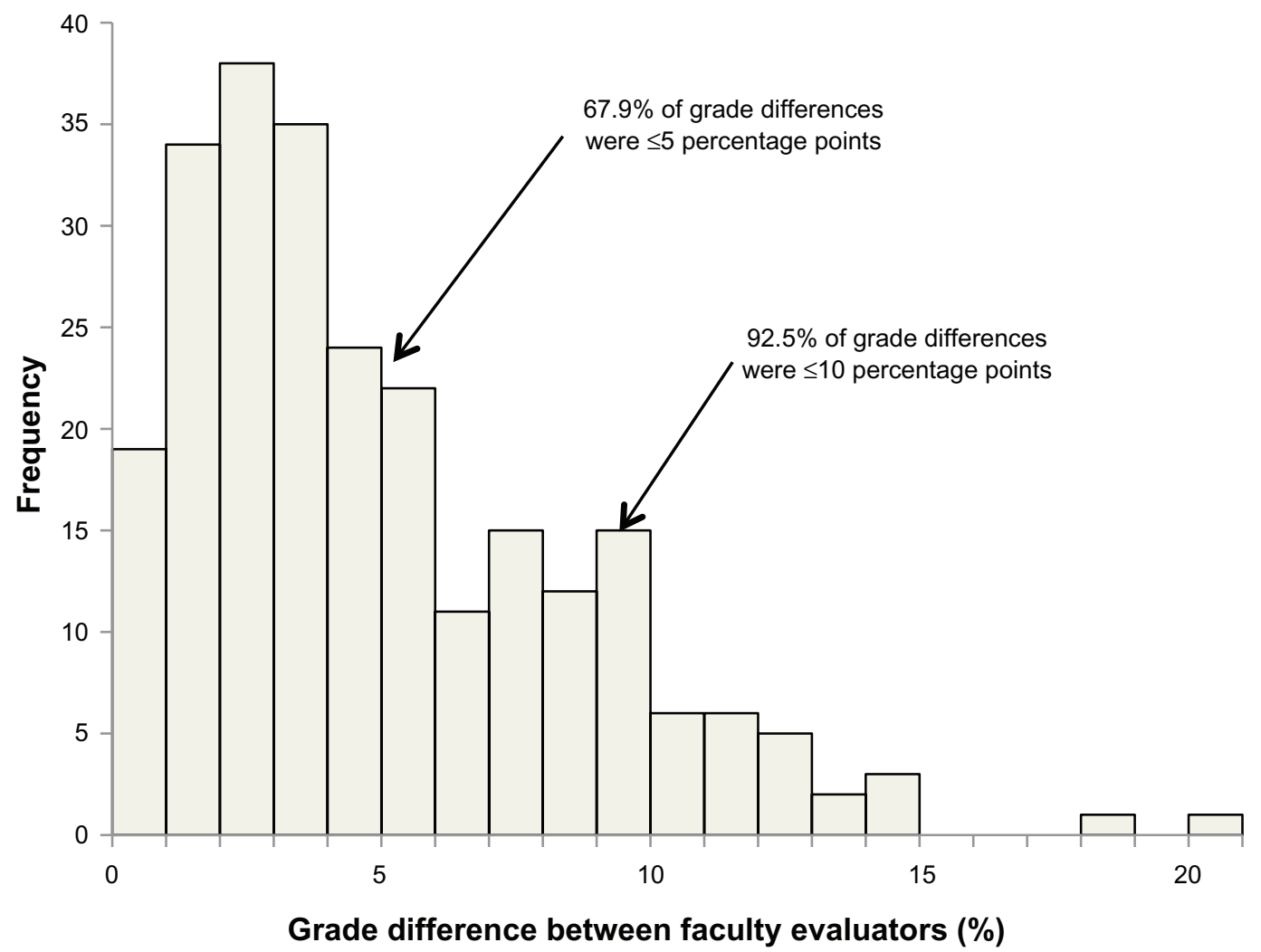

Figure I Histogram depicting the differences in score between faculty graders. 
Table 2 Grade difference of faculty pairs stratified by differences in academic rank

\begin{tabular}{llllll}
\hline $\begin{array}{l}\text { Difference in } \\
\text { academic rank }^{\mathbf{a}}\end{array}$ & $\mathbf{N}$ & $\begin{array}{l}\text { Mean grade } \\
\text { difference }^{\mathbf{b}}\end{array}$ & Std deviation & \multicolumn{2}{l}{$\mathbf{9 5 \% \text { Confidence interval for mean }}$} \\
\hline 0 & 83 & 4.36 & 3.03 & 3.6996 & Upper bound \\
\hline & 78 & 4.69 & 4.07 & 3.7681 & 5.0233 \\
2 & 59 & 4.95 & 4.07 & 3.8864 & 5.6047 \\
3 & 32 & 3.89 & 2.91 & 2.8427 & 6.0051 \\
\hline
\end{tabular}

Notes: academic rank of faculty pair: 0 represents same rank, I represents a difference of one level of rank (eg, assistant professor and associate professor), 2 represents a difference of two levels of rank (eg, assistant professor and professor), 3 represents a difference of three levels of rank (instructor and professor); ${ }^{b}$ No difference in scores were noted across faculty ranks by one-way analysis of variance $(P=0.553)$.

for the presentation, quintiles (ie, $0 \%-19 \%, 20 \%-39 \%$, $40 \%-59 \%, 60 \%-79 \%, 80 \%-100 \%$ ) were used to characterize low versus high performing students. As can be seen in Figure 2, mean differences between student and faculty scores differed by quintile $(3.41,0.66,-2.30,-3.98,-3.71$, for lowest to highest quintile, respectively). Students in the lowest quintile overestimated their performance by a mean of 3.41 points and students in the upper quintiles underestimated their performance $(\mathrm{F}(4,243)=18.336, P<0.001)$. This finding was confirmed by the correlation of faculty scores with the difference of student and faculty scores; $\mathrm{r}=-0.541, \mathrm{n}=248$, $P<0.001$. Low performing students overestimated their performance and high performing students underestimated their performance.

\section{Discussion}

To our knowledge, this is the first study to assess and characterize a seminar grading rubric in a health professions curriculum. Internal consistency (a necessary condition for construct validity) of this tool was acceptable (Cronbach's alpha $=0.826$ ), demonstrating that the 15 items in the rubric consistently measured students' presentation outcomes. In addition, the inter-rater grade agreement analysis demonstrated consistency in presentation assessments. Inter-rater agreement was not biased by student age, gender, or race and did not vary significantly based upon campus, over time (ie, between semesters), or faculty rank.

While the aim of the current study was not to determine the validity of the rubric, components of validity were

Table 3 Correlation between student self-evaluation and faculty presentation scores $^{a}(n=252)$

\begin{tabular}{lll}
\hline $\begin{array}{l}\text { Grand rounds } \\
\text { rubric component }\end{array}$ & $\begin{array}{l}\text { Pearson } \\
\text { correlation }\end{array}$ & P-value \\
\hline Content scores & 0.513 & $<0.00$ I \\
Communication scores & 0.455 & $<0.00$ I \\
Overall presentation scores & 0.539 & $<0.001$ \\
\hline
\end{tabular}

Note: 'Faculty presentation score was the student's final presentation grade (ie, average of faculty grader I and 2 scores). addressed. Content validity was established by basing the rubric upon established methods including a thorough review of the literature as well as informal polling of other pharmacy institutions. In addition, the rubric was reviewed by faculty with expertise in pharmacy education to validate that the items were appropriate or valid. Furthermore, convergent validity was supported by the acceptable level of internal consistency.

Findings of the current study regarding differences in student perceptions of their performance compared to the faculty graders were consistent with those of others. ${ }^{12-14}$ Students with grades in the lower quintiles self-evaluated their performance higher than the faculty, whereas students who were in the highest quintiles rated their performance lower than faculty. This suggested that students who performed poorly may have limited insight into weaknesses and overestimated their strengths, whereas students who performed well underestimated their strengths and overestimated weaknesses.

Despite the strengths of the current study, there are some limitations. With respect to external validity, our findings should only be generalized to education programs with student and faculty characteristics similar to ours Due to lack of a "standard" seminar grading form, we were not able to demonstrate criterion validity for this grading tool.

Another limitation of the study was some instances of large disparities (ie, $>10$ points) between faculty graders. While the difference in faculty evaluations for the majority of presentations were less than 5 percentage points, there were instances in which faculty differed by more than 10 points, despite an effort to orient faculty to the grading rubric and providing detailed directions. However, averaging the two faculty evaluations mitigated most of the differences. A formal training session for faculty involved in the grading process may have yielded improved interrater grade agreement, and should be considered in the future. 


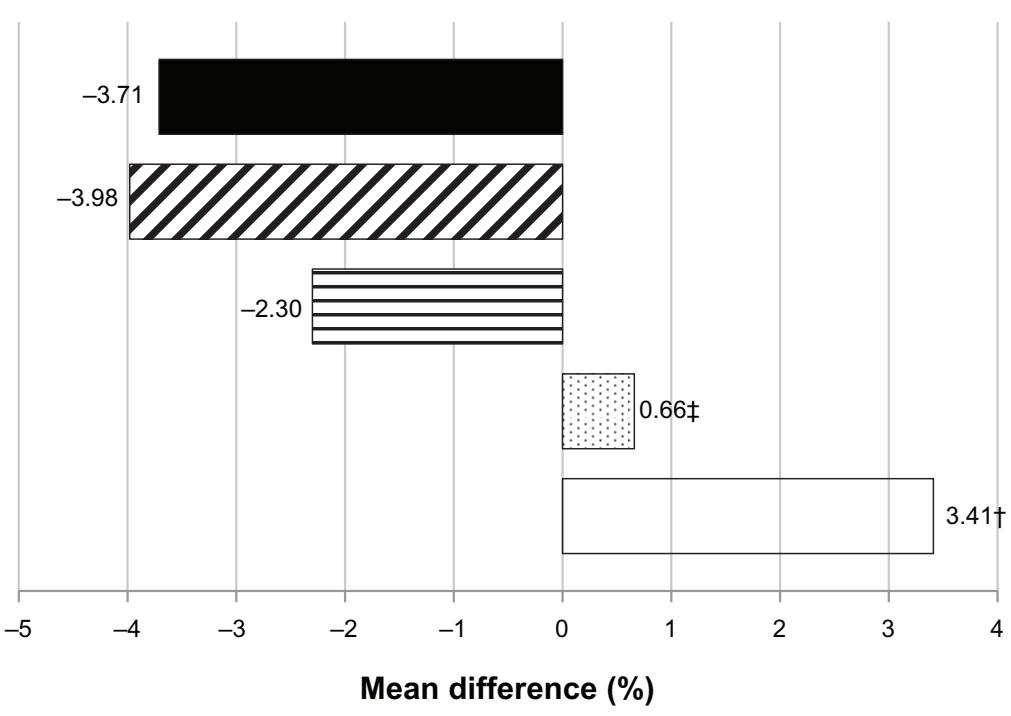

\section{Quintile}

$5(\geq 80 \%$; Score range $>95.5 \%, n=47)$

$4(60 \%-79 \%$; Score range $92.6 \%-95.5 \%, n=51)$

曰 $3(40 \%-59 \%$; Score range $89.6 \%-92.5 \%, n=52)$

궁 $2(20 \%-39 \%$; Score range $85.1 \%-89.5 \%, n=50)$

$1(\leq 19 \%$; Score range $<85 \%, n=48)$

Figure 2 Differences between student self-evaluation and faculty presentation scores by quintile. ${ }^{\mathrm{a}}$

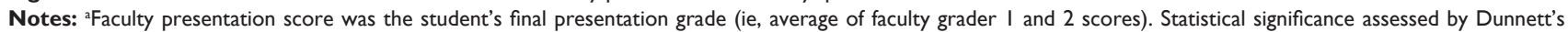
T3 post hoc test. A negative value indicates that the student's score was less than the mean faculty grader score and a positive value indicates that it was greater; ${ }^{\dagger}$ Differs

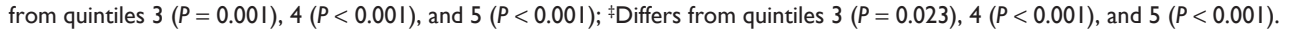

\section{Conclusion}

The seminar evaluation rubric demonstrated inter-rater grade agreement and internal consistency. While this rubric was designed specifically for a pharmacy curriculum, it could be easily adapted for use by other health professional programs that require formal student presentations. Significant correlation between faculty evaluations and students' selfassessment was noted. Similarly, there was generally good agreement between faculty grader pairs. Consistent with prior research, students who performed poorly rated their selfperformance higher than the faculty. Likewise, students who performed well rated their performance lower than the faculty. Future studies should be conducted to determine if similar results would be seen if the rubric were used in other health professional curricula that require a formal presentation. It would also be useful to identify other faculty-associated factors that may result in grade disparities (eg, academic background, years of experience) and how these may be mitigated. In addition, it would be useful to assess the impact of student self-assessment on future public speaking activities to determine if performance is improved.

\section{Acknowledgments}

We would like to acknowledge Dr Melissa Medina from the University of Oklahoma who developed and shared her seminar grading form, and was of assistance in developing our form. In addition, we would like to thank Mrs Toni Bryan for her assistance with data entry.

\section{Disclosure}

The authors report no conflicts of interest in this work.

\section{References}

1. The core competencies needed for health care professionals. In: Greiner AC, Knebel E, editors. Health professions education: a bridge to quality. The National Academy of Sciences; 2003:45-73.

2. Accreditation Standards and Guidelines for the professional program in pharmacy leading to the doctor of pharmacy degree. Accreditation Council for Pharmacy Education. Available at http://www.acpe-accredit. org/pdf/ACPE_Revised_PharmD_Standards_Adopted_Jan152006.pdf. Accesed May 14, 2010.

3. Functions and structure of a medical school: standards for accreditation of medical education programs leading to the M.D. degree. Liaison Committee on Medical Education. Available at: http://www.lcme.org/ standard.htm. Accessed Jun 25, 2010.

4. Hatala R, Guyatt G. Evaluating the teaching of evidence-based medicine. JAMA. 2002;288(9):1110-1112.

5. NLNAC Standards and criteria for baccalaureate degree (2008). National League for Nursing Accrediting Commission, Inc. Available at: http:// www.nlnac.org/manuals/SC2008.htm. Accessed Jun 25, 2010.

6. NLNAC Standards and criteria for clinical doctorate degree (2008). National League for Nursing Accrediting Commission, Inc. Available at: http://www.nlnac.org/manuals/SC2008.htm Accessed Jun 25, 2010.

7. Accreditation standards for continuing pharmacy education: effective January 1, 2009. Accreditation Council for Pharmacy Education. Available at: http://www.acpe-accredit.org/ceproviders/standards.asp. Accessed Jun 25, 2010.

8. Beardsley RS. Communication skills development in colleges of pharmacy. Am J Pharm Educ. 2001;65:307-314.

9. Poirier TI. A seminar course on contemporary pharmacy issues. Am J Pharm Educ. 2008;72(2):30.

10. DeVon HA, Block ME, Moyle-Wright P, et al. A psychometric toolbox for testing validity and reliability. J Nurs Scholarsh. 2007;39(2): 155-164.

11. van der Vleuten CP, Schuwirth LW. Assessing professional competence: from methods to programmes. Med Educ. 2005;39(3):309-317. 
12. Stefani LAJ. Peer, self and tutor assessment: Relative reliabilities. Studies in Higher Education. 1994;19(1):69.

13. Albanese M, Dottl S, Mejicano G, et al. Distorted perceptions of competence and incompetence are more than regression effects. $A d v$ Health Sci Educ Theory Pract. 2006;11(3):267-278.
14. Eva KW, Cunnington JP, Reiter HI, Keane DR, Norman GR. How can I know what I don't know? Poor self assessment in a well-defined domain. Adv Health Sci Educ Theory Pract. 2004;9(3):211-224. 


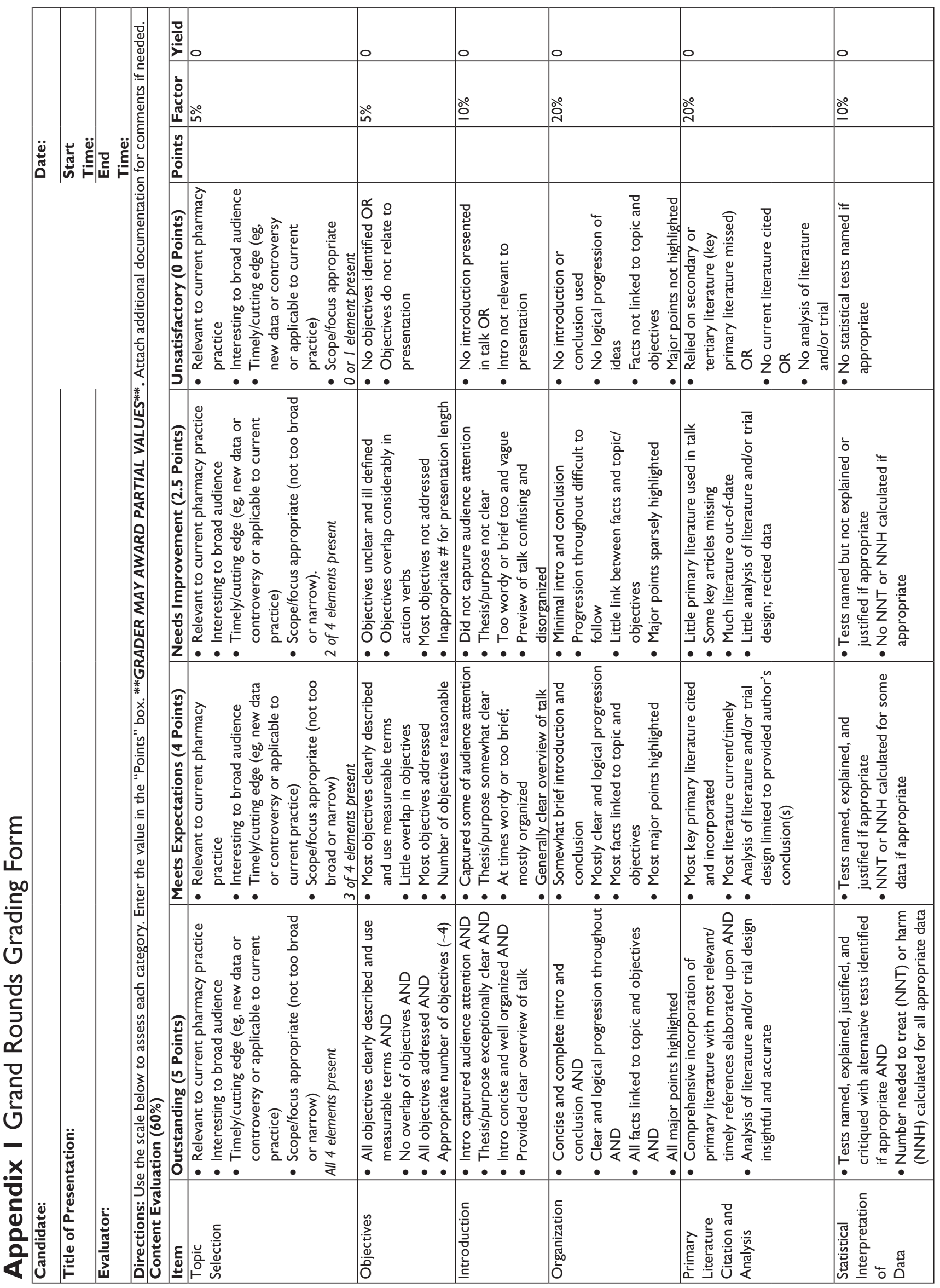




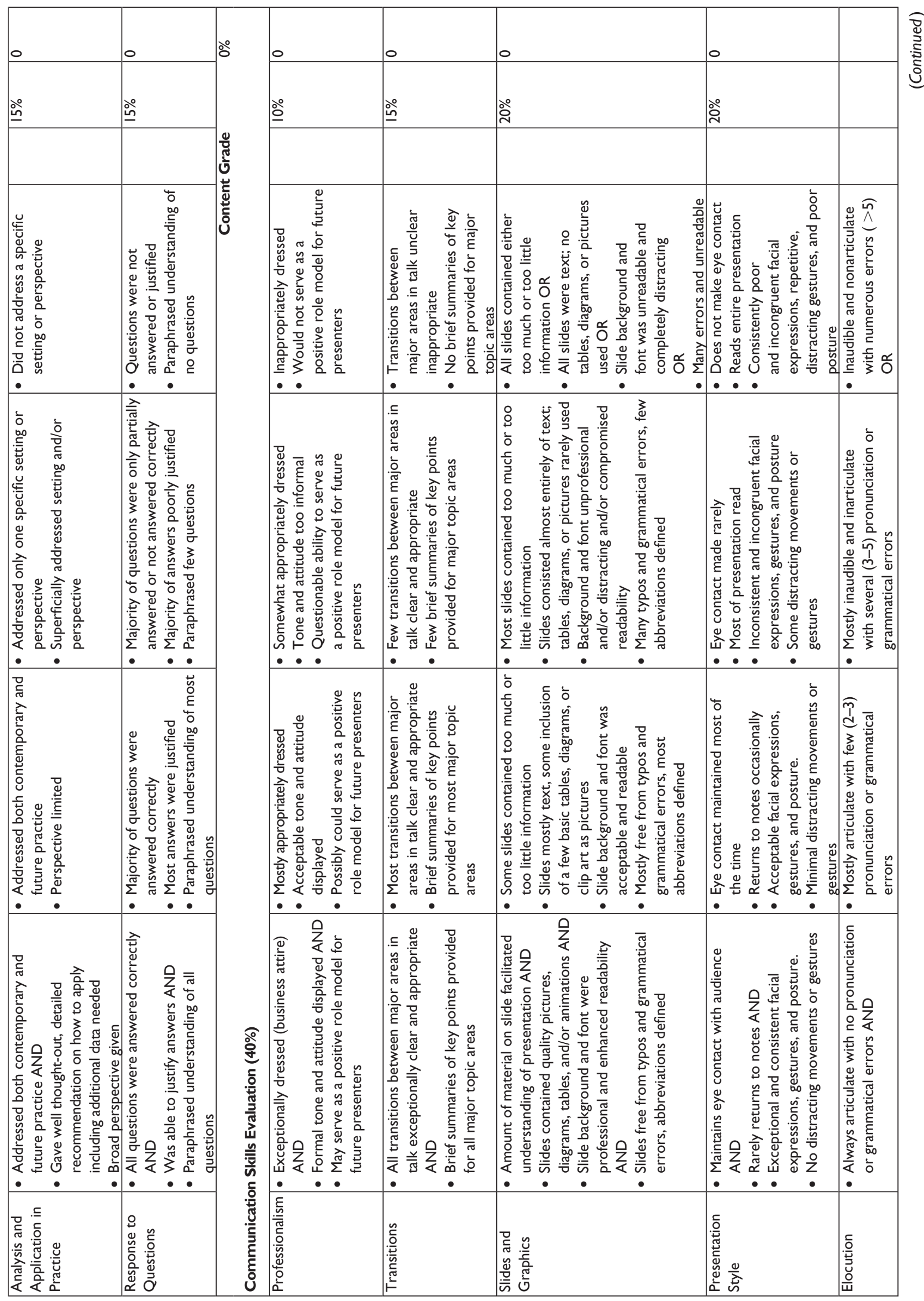




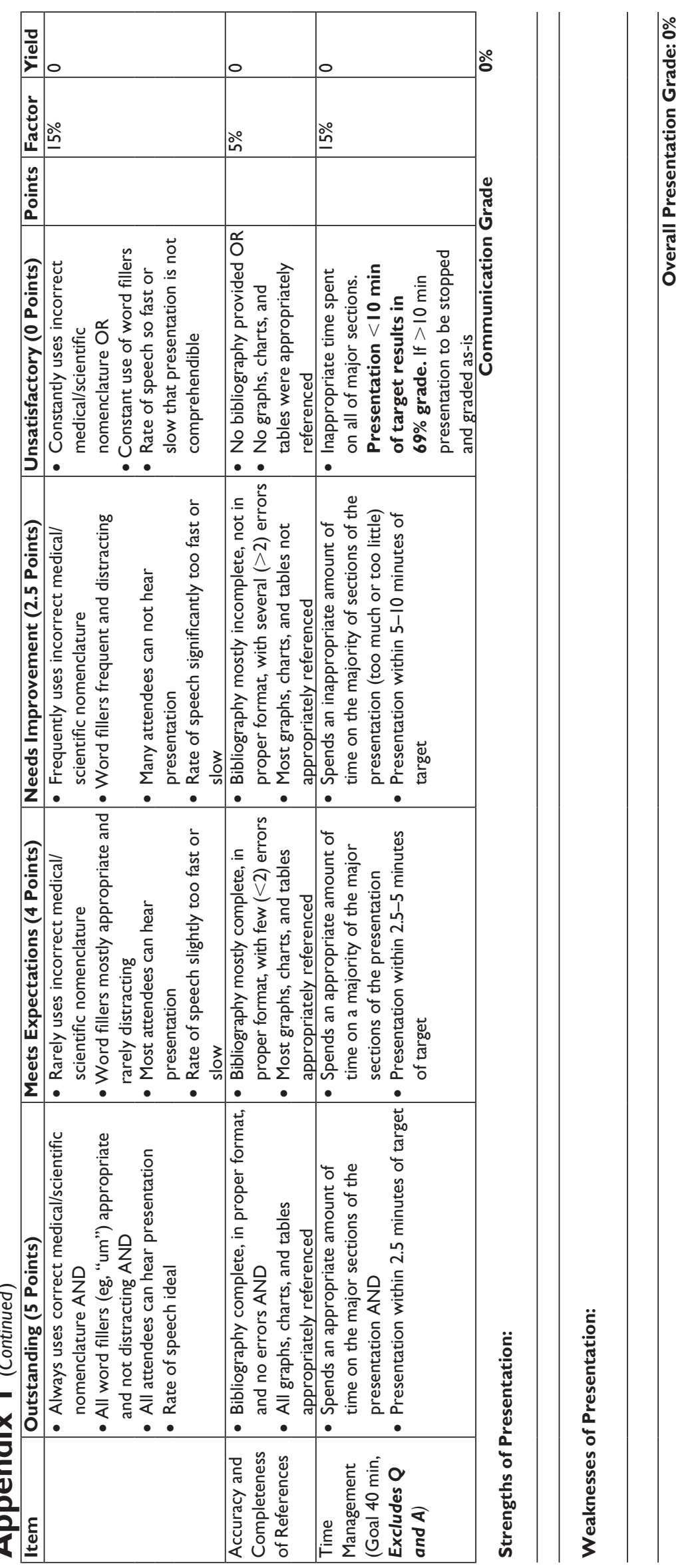


Journal of Multidisciplinary Healthcare

Dovepress

\section{Publish your work in this journal}

The Journal of Multidisciplinary Healthcare is an international, peerreviewed open-access journal that aims to represent and publish research in healthcare areas delivered by practitioners of different disciplines. This includes studies and reviews conducted by multidisciplinary teams as well as research which evaluates the results or conduct of such teams or healthcare processes in general. The journal covers a wide range of areas and welcomes submission from practitioners at all levels, from all over the world. The manuscript management system is completely online and includes a very quick and fair peer-review system. Visit http://www.dovepress.com/testimonials.php to read real quotes from published authors.

Submit your manuscript here: http://www.dovepress.com/journal-of-multidisciplinary-healthcare-journal 